\title{
GAMETOGENESIS IN DIATRAEA SACCHARALIS (FABR.)
}

The crambid moth Diatraea saccharalis (Fabr.) is known as a severe pest of sugarcane in the New World. The Department of Entomology of this Station, in cooperation with the Plant Breeding Department (Río Piedras Station), the Puerto Rico Nuclear Center, and the College of Sciences of the University of Puerto Rico at Mayagüez, recently started experiments to induce sterility in the moth by means of irradiation treatments with gamma rays. Thus, it appeared advisable first to investigate the cytology of the gametogenesis. The present Note is a preliminary account of the results obtained and will be supplemented later by a more detailed paper.

The spermatogenesis of Diatraea saccharalis can be divided into two different periods, the normal and the asynaptic. Before the sixth day of larval life the testes contain primordial and younger spermatogonia. From the sixth day on first meiotic divisions occur in the proximal end of each testis follicle. From the 15th day on the larvae contain all stages from spermatogonia to spermatids of different age.

There are 17 bivalents in the first (reduction) metaphase of meiosis (fig. 1, A,a). The anaphase is normal, and 17 chromosomes appear in the second metaphase. The centromeres seem diffuse (fig. 1, A,b).

In the pupae, the meiosis is asynaptic. In the first day of pupal life, there are still normal metaphases and anaphases, but among them there are also cells with complete lack of chromosome pairing. From the second pupal day on, only asynaptic spermatocytes occur (fig. 1, B).

At the end of the asynaptic reduction metaphase, the homologues tend to pair, or coorientate shortly. This results in a correct segregation $17+$ 17 fairly often, but irregular divisions are more common (fig. 1, C). It is possible that the asynaptic spermatogenesis is 100 -percent sterile.

No more divisions occur in the adult male. Some spermatogonia and prophasic spermatocytes are left, but the main contents of the testes comprise spermatozoon bundles and spermiohistogenetic spermatids.

In the female, the oocytes, remaining in diplotene (dictyotene), grow slowly during the second half of larval life, and the pupal stage. A rapid deposition of yolk begins at the end of pupal stage, and continues in the adult female. Meiotic divisions begin in the old, flattening ovarial eggs. 
A

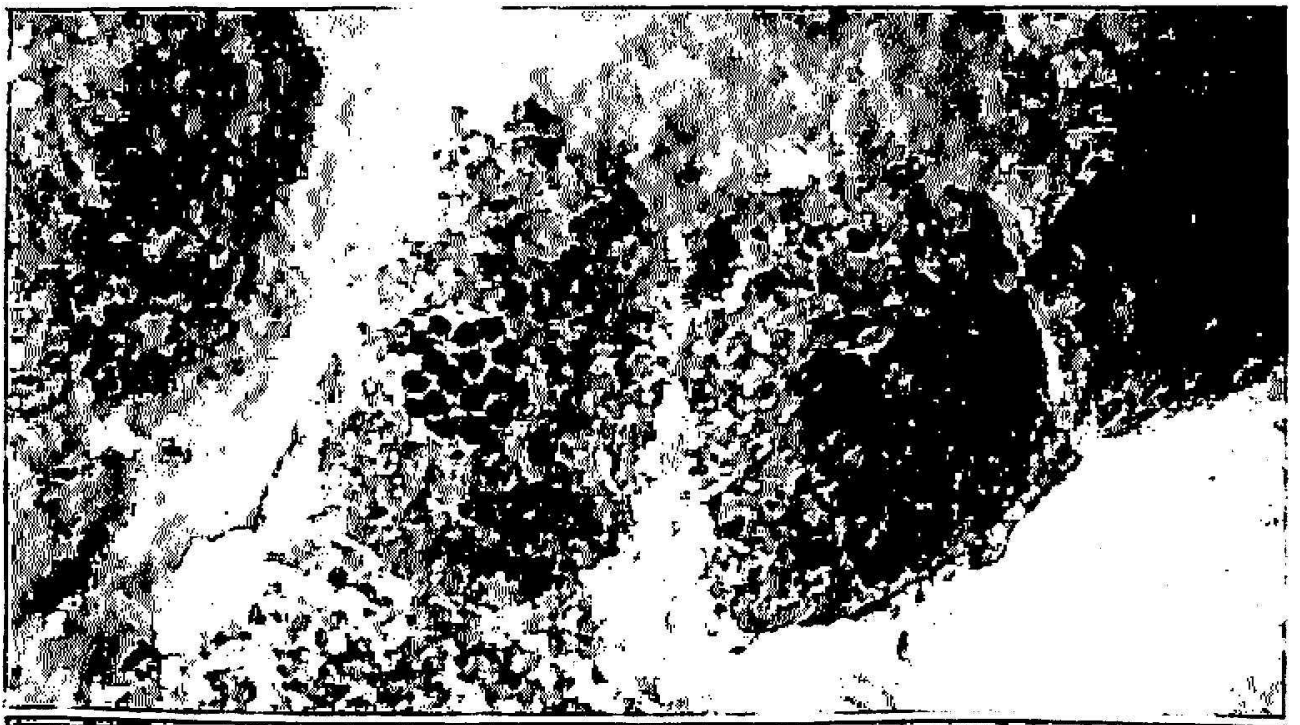

B
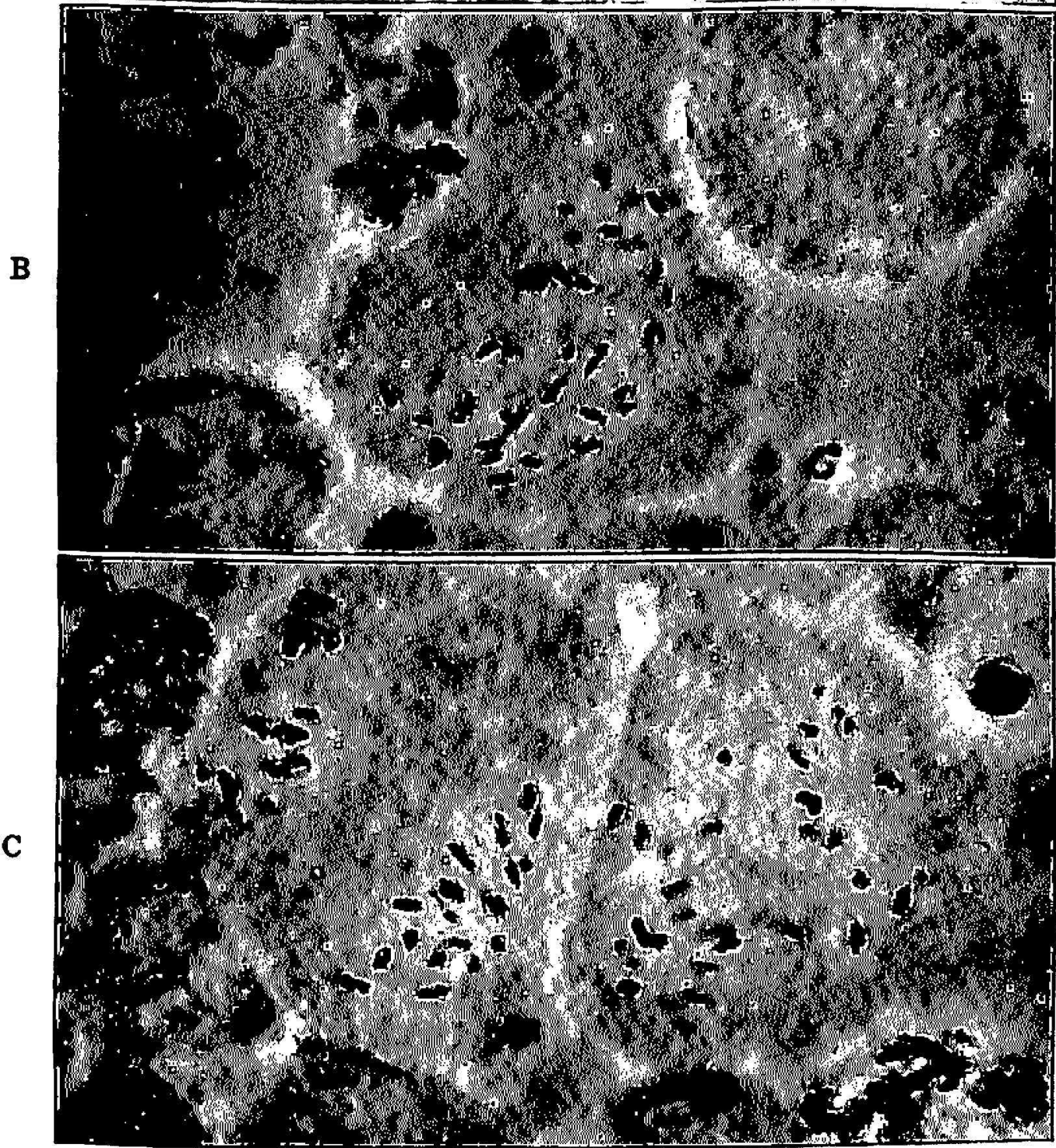

Fig. 1.-Chromosome relations in the spermatogenesis of Diatraea sarcharalis: $A$, Reduction metaphases from a larva of 28 days; $a, 17$ bivalents are in polar view; b, a profile view showing double spindle fibers; sectioned preparation. $B$, Asynaptic prometaphase I from a pupa of 6 days showing 34 univalents; squash preparation. C, Reduction anaphases from a pupa of 5 days; nearly correct segregation; squash preparation. Magnification $1680 \times$ in all photographs. 
The findings provide the following tabular guide for irradiations of the male:

$$
\text { Cell type to be irradialed }
$$

Cleavage cells

Primordial spermatogonia

Spermatogonia and meiotic prophase

All stages of meiosis and spermiohistogenesis

Asynaptic meiosis and spermiohistogenesis
Slage and age where most absundantly
acailable

Eggs in the morning following oviposition

Larvae of 2-4 days

Larvae of 7-10 days

Larvae of $15-33$ days

Pupae

Spermiohistogenesis and spermatozoa in bundles Adults

The best period to encounter all stages except spermatozoa are the 2 last weeks of larval life. Because the spermatogenesis proceeds continuously from the distal end towards the apex of the testis follicles, there are no essential changes in the frequency of the different phases during this period. The number of spermatogonia decreases, of course, and the number of spermatids increases, but both are present.

As the spermatogenesis of the pupa is highly, probably completely sterile, male pupae serve only for irradiation of spermatids and spermatozoa.

As to the female, oogonia can be encountered at the same age as spermatogonia. Early meiotic prophase lasts during most of the life cycle. If the yolk deposition should be disturbed, old pupae and young adults should be treated.

The above guide is based on material reared in warm, humid, tropical lowlands in Río Piedras. Where such climatic conditions as cold or drought cause prolongation of the development, the data must be modified accordingly. In longer drought diapause, or hibernation, the same will probably happen as in Arctic and Subarctic arthropods during the winter: the spermatocytes beyond pachytene disappear, and some accumulation of pachytene and leptotene occurs. 